\title{
PKM Guru Matematika MTs Swasta Kecamatan Jabung Kabupaten Malang Jawa Timur
}

\author{
Kawakibul Qamar', Selamet Riyadi ${ }^{2}$, Yusriel Ardian ${ }^{3}$ \\ ${ }^{1,3}$ Program Studi Sistem Informasi, Fakultas Sains dan Teknologi, Universitas Kanjuruhan -Malang \\ ${ }^{2}$ Program Studi Pendidikan Matematika, Fakultas Sains dan Teknologi, Universitas Kanjuruhan -Malang \\ E-mail: ikings94@unikama.ac.id. 08170500294
}

\begin{abstract}
ABSTRAK
Program Kemitraan Masyarakat (PKM) Guru Matematika bertujuan untuk meningkatkan kualitas pembelajaran dengan memanfaatkan software aplikasi freeware matematika yang bebas biaya lisensi sebagai media pembelajaran. Kegiatan ini difokuskan pada guru Matematika di kecamatan Jabung Kabupaten Malang yang mengabdi di MTs Ahmad Yani dan MTs Ar-Rahmah. Dari hasil wawancara dengan kepala sekolah dan beberapa guru, ditemukan masalah antara lain banyak guru yang belum pernah mendapatkan kesempatan untuk mengikuti pelatihan/workshop pemanfaatan software matematika sebagai media pembelajaran sehingga mengakibatkan rendahnya kreativitas guru dalam memilih model, metode atau pendekatan dalam mengajarkan konsep dasar matematika. Begitu juga dengan jangkauan teknologi informasi yang masih sangat kurang, sehingga guru ataupun sekolah, kurang mendapatkan informasi atau perkembangan software khususnya dalam pembelajaran matematika. Untuk menyelesaikan permasalahan diatas maka perlu melakukan pendampingan terhadap guru matematika dalam menggunakan media pembelajaran berbantuan komputer dalam rangka meningkatkan kemampuan dan kreativitas guru. Metode yang ditawarkan dengan memberi workshop agar mengenal software aplikasi freeware matematika.
\end{abstract}

Kata kunci : pendampingan; guru matematika; media pembelajaran

ABSTRACT

Program Kemitraan Masyarakat (PKM) Mathematics Teachers aim to improve the quality of learning by utilizing mathematical freeware application software that is free of license fees as a learning media. This activity was focused on Mathematics teachers in MTs Ahmad Yani and MTs Ar-Rahmah. From the results of interviews with principals and several teachers were found problems where many teachers who never had the opportunity to attend training/workshop on the use of mathematical software as learning media, which resulted in the teacher's lack of creativity in choosing models, methods or approaches in teaching basic mathematical concepts. Even the teacher's skill of information technology is less, so that teachers or schools lack information or software development, especially in learning mathematics. To solve the problems, it needs to provide assistance to the mathematics teacher in using computer-assisted learning media in order to improve the ability and creativity of the teacher. The method offered by giving workshops to upgrade their skill in mathematical freeware application software.

Keywords : mentoring; mathematics teacher; learning media. 


\section{PENDAHULUAN}

Kabupaten Malang merupakan salah satu kabupaten dari Provinsi Jawa Timur. Kabupaten ini berada di selatan provinsi Jawa Timur yang membatasi Kota Malang dan juga dibatasi oleh Kabupaten Pasuruan, Kota Batu, Kabupaten Blitar dan juga Kabupaten Lumajang. Kecamatan Jabung merupakan salah satu kecamatan yang berada di sebelah timur yang berjarak $\pm 25 \mathrm{~km}$ dari pusat pemerintahan Kabupaten Malang. Kecamatan Jabung memiliki satu jalan kabupaten yang cukup lebar namun lebih banyak jalan kecil yang menghubungkan antar desa.

Kecamatan Jabung memiliki 3 Sekolah Menengah Pertama Negeri sedangkan sekolah lainnya adalah sekolah swasta termasuk didalamnya adalah sekolah setara SMP yaitu Madrasah Tsanawiyah (MTs). Adapun semua MTs di kecamatan Jabung berstatus sekolah swasta. Jumlah toal terdapat 4 MTs swasta yang secara konsisten membantu pemerintah dalam mencerdaskan kehidupan generasi penerus bangsa. MTs tersebut terletak di desa pinggiran yang jauh dari pusat pemerintahan kecamatan Jabung, yaitu MTs Ahmad Yani, MTs Al Hidayah, MTs Ar-Rahmah dan MTs Islamiyah.

MTs Ahmad Yani beralamatkan di jalan Raya 145 Sukolilo kecamatan Jabung, kabupaten Malang. Sekolah ini terletak pinggir timur kecamatan Jabung, tepatnya $\pm 15 \mathrm{~km}$ dari terminal Arjosari Malang, atau sekitar $21 \mathrm{~km}$ dari Universitas Kanjuruhan. Transportasi menuju ke MTs Ahmad Yani dapat menggunakan gabungan transportasi umum seperti angkutan kota (angkot) kemudian angkutan pedesaan (angdes), namun frekuensi angkot serta angdes relatif sepi dan sedikit sehingga lebih efektif dan efisien menggunakan ojek atau kendaraan pribadi yaitu sepeda motor atau mobil.

Sekitar $2 \mathrm{~km}$ ke arah Utara tepatnya Jl. Sidodadi 28 Bendo kecamatan Jabung terdapat MTs Ar-Rahmah. Letak MTs Ar-Rahmah memiliki kesamaan dalam akses transortasinya. Akses menuju ke MTs Ar-Rahmah lebih mudah jika menggunakan kendaraan pribadi, karena angkutan umum tidak ada yang melewatinya, kecuali ojek. Adapun kegiatan kedua sekolah ini mengandalkan swadaya masyarakat sekitar dan bantuan operasional sekolah dari Depag kabupaten Malang.

Tim pengabdi memfokuskan pada MTs Ahmad Yani dan MTs Ar-Rahmah sebagai pihak Mitra Pengabdi. Baik Pihak Mitra 1 yaitu MTs Ahmad Yani dan Pihak Mitra 2 yaitu MTs Ar-Rahmah merupakan MTs Swasta yang tergolong sekolah dengan fasilitas yang sangat terbatas. Keterbatasan fasilitas dan kurangnya kegiatan pelatihan yang diikuti oleh guru membuat kemampuan guru dalam pemanfaatan IT atau softwaresoftware aplikasi matematika masih sangat kurang. Hasil wawancara dengan kedua Kepala Sekolah yang dilakukan pada bulan Desember 2016 diperoleh informasi bahwa frekuensi keterlibatan guru dalam mengikuti pelatihan tingkat provinsi atau tingkat nasional masih sangat kecil. Oleh karena itu kemampuan guru dalam memanfaatkan software dalam pembelajaran maupun administrasi 
pembelajaran masih sangat rendah. Hal ini terlihat dari hasil pengetikan naskah soal matematika yang masih terlihat tidak sesuai dengan kaidah penulisan rumus yang baku.

Penguasan teknologi informasi saat ini sangat diperlukan karena mempengaruhi semua aspek kehidupan termasuk dibidang pendidikan. Bidang pendidikan khususnya pembelajaran matematika di tingkat sekolah dasar maupun menengah telah banyak berkembang media atau alat bantu yang dapat digunakan dalam mengajarkan konsep dasar matematika[1], [2]. Namun, pada saat observasi di pihak mitra diketahui bahwa kegiatan pembelajaran yang masih bersifat konvensional (mencatat, ceramah, tugas rumah) sehingga berdampak pada kebosanan siswa dan kurangnya pemahaman konsep dasar. Kedua sekolah Mitra baik MTs Ahmad Yani dan MTs Ar-Rahmah sangat minim akses teknologi pembelajaran. Hal ini terlihat dari alokasi dana sekolah yang memfokuskan pada sarana fisik dan sarana pembelajaran yang dimiliki kedua sekolah, yaitu hanya memiliki 1 LCD proyektor, 1 laptop.

Banyak faktor yang mempengaruhi pelaksanaan pembelajaran yang menarik minat siswa[3], seperti (1) lokasi sekolah dan kondisi siswa sehingga mematahkan semangat guru dalam menciptakan pembelajaran yang inovatif, keterbatasan sarana dan prasarana, serta (3) minimnya pengetahuan dan kemampuan menggunakan media pembelajaran yang maju seperti penggunaan komputer. Alasan-alasan yang umum disampaikan oleh para guru dari hasil wawancara ditemukan masalah seperti pengembangan fasilitas komputer/LCD di sekolah yang tidak lengkap dikarenakan tidak adanya dana untuk pengadaan, serta sikap guru yang lambat dalam merespon kemajuan ICT.

Berdasarkan kondisi pembelajaran tersebut, maka peran guru dalam menciptakan pembelajaran yang efektif, efisien dan interaktif mutlak diperlukan[4]. Akan tetapi, banyak keterbatasan-keterbatasan yang dialami oleh guru maupun sekolah, seperti: (1) kurangnya media yang memadai, (2) Kurangnya kreativitas guru dalam merancang media pembelajaran, karena guru sangat jarang mengikuti pelatihan merancang media pembelajaran.

Untuk mengantisipasi supaya permasalahan diatas tidak terjadi maka diperlukan sosok guru yang mampu menguasai model-model pembelajaran yang tepat yang nantinya mampu memotivasi siswa dalam belajarnya. Salah satu model pembelajaran yang tepat yang dapat ditawarkan adalah model pembelajaran matematika berbasis media, karena dengan media diharapkan siswa lebih tertarik, aktif, kreatif, konstruktif, dan termotivasi dalam belajarnya[1]. Demi tercapainya model pembelajaran ini maka seorang guru diharapkan memiliki kemampuan dalam mengoperasikan media yang akan digunakannya. Diperlukan suatu pelatihan khusus untuk dapat membantu guru bisa mengoperasikan media tersebut. Oleh sebab itu tim pengabdi tertarik untuk membantu menyelesaikan yaitu dengan menyelenggarakan pelatihan pembuatan media pembelajaran 
berbantuan komputer dalam rangka meningkatkan kemampuan dan kreativitas para guru.

Permasalahan Mitra diketahui melalui wawancara dan observasi. Beberapa permasalahan dan kendala tersebut sebagai berikut:

1. Sebagian besar guru belum pernah mendapatkan kesempatan untuk mengikuti pelatihan/workshop pemanfaatan software matematika sebagai media pembelajaran.

2. Masih rendahnya kreatifitas guru dalam memilih model, metode atau pendekatan dalam mengajarkan konsep dasar matematika

3. Jangkauan teknologi informasi yang masih sangat kurang, sehingga guru ataupun sekolah, kurang mendapatkan informasi atau perkembangan software khususnya dalam pembelajaran matematika.

4. Keinginan sekolah/guru untuk meningkatkan kualitas sumber daya manusia sangat tinggi, namun terkendala oleh banyak faktor seperti pendanaan, jangkauan teknologi, fasilitas sekolah, kesempatan mengikuti pelatihan dll.

5. Program nasional tentang pelatihan guru matematika yang berorientasi pada pemanfaatan software hanya diikuti oleh sekolah-sekolah tertentu yang berada dekat pusat kabupaten.

\section{METODE KEGIATAN}

Berdasarkan analisis situasi dan permasalah yang dihadapi oleh mitra, dosen sebagai pelaksanan kegiatan pengabdian yang dibantu oleh mahasiswa sebanyak 5 orang orang sebagai tenaga profesional dari perguruan tinggi akan memberikan suatu solusi untuk mengatasi kesulitan guru dalam memanfaatkan software untuk visualisasi objek-objek matematika.

Alih pengetahuan dan teknologi kepada guru melalui beberapa cara, seperti: pemanfaatan software aplikasi Matematika. Pendampingan dilakukan dengan metode diskusi dan sharing, monitoring yang kemudian dilakukan evaluasi terhadap pelatihan ini[5]. Untuk meminimalkan biaya pelatihan dan beban sekolah maka digunakanlah aplikasi freeware Geogebra dan fitur rumus pada pengolah kata yang memiliki sistem bebas tanpa biaya lisensi, namun tidak mengurangi kualitas hasil media pembelajaran[6].

Langkah-langkah solusi atas permasalahan mitra

1) Pendampingan pemanfaatan software aplikasi Matematika

Pendampingan ini dilaksanakan berdasarkan 3 tema kegiatan. Rencana kegiatan ditampilkan dalam setiap akhir pekan sebagai berikut:

a. Tema minggu pertama adalah Workshop pemanfaatan Software Geogebra sebagai media pembelajaran.

b. Tema minggu kedua adalah workshop penulisan rumus matematika menggunakan pengolah kata.

c. Tema minggu ketiga adalah workshop pembuatan media pembelajaran matematika. 


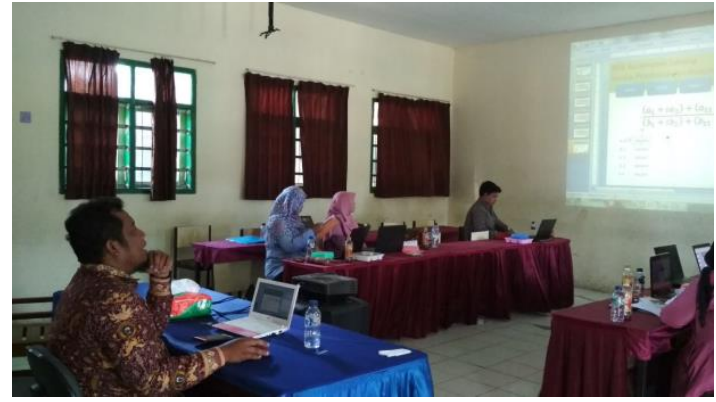

Gambar 1. Pelaksanaan Workshop

\section{2) Diskusi dan Sharing}

Kegiatan diskusi dilaksanakan pada saat penyampaian materi saat workshop dan saat berkelompok. Sedangkan Sharing dilakukan saat wakil dari masing-masing kelompok mata pelajaran menampilkan hasil/karya dari kelompok mata pelajaran. Pada kegiatan sharing ini, kelompok lain boleh bertanya, atau mengkritisi hasil karya dari setiap pelatihan yang ditampilkan berdasarkan kriteria yang telah disampaikan pada saat workshop.

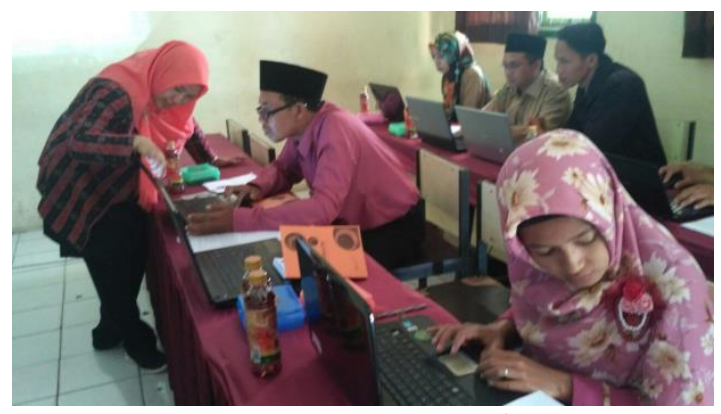

Gambar 2. Diskusi dan Sharing

\section{3) Monitoring dan Evaluasi Pelaksanaan}

Untuk memastikan keberhasilan kegiatan pelndampingan ini, maka direncanakan kegiatan monitoring serta evaluasi dari pelaksanaan pembelajaran menggunakan media pembelajaran yang sudah dibuat. Waktu pelaksanaan monitoring dilakukan sesuai dengan materi yang telah dibuat oleh peserta kegiatan. Sedangkan yang bertindak sebagai observer adalah tim kegiatan pelatihan yang dibagi berdasarkan jadwal pembelajaran yang sudah disepakati oleh peserta kegiatan. Adapun kegiatan evaluasi dilakukan serempak dengan memperhatikan berakhirnya monitoring. Sehingga di akhir kegiatan akan dikumpulkan kembali untuk diberikan tambahan saran serta koreksi berdasarkan hasil evaluasi.

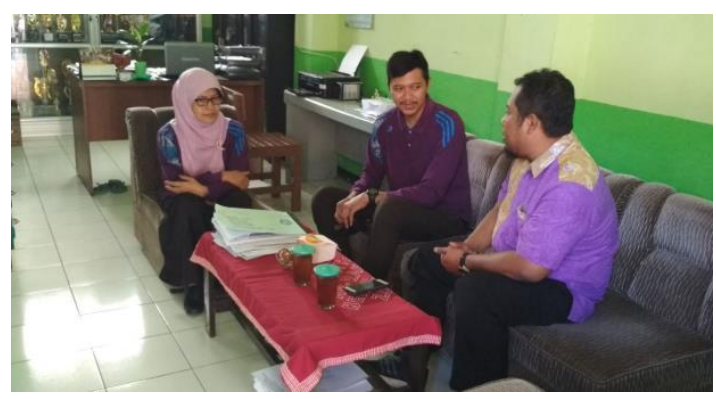

Gambar 3. Monitoring dan Evaluasi

\section{KARYA UTAMA}

Pada workshop pertama, para peserta berlatih untuk mengenal dan membuat grafik menggunakan aplikasi Geogebra. Manfaat geogebra adalah memudahkan peserta dalam menggambar grafik yang biasanya diperlukan dalam pembelajaran baik dalam bentuk latihan, soal dan penguatan di media pembelajaran. Beberapa gambar yang dihasilkan sebagai berikut.

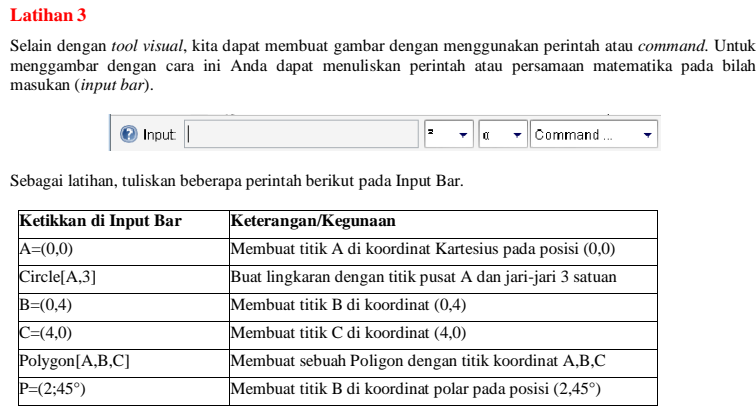

Gambar 4. Latihan dalam Geogebra 


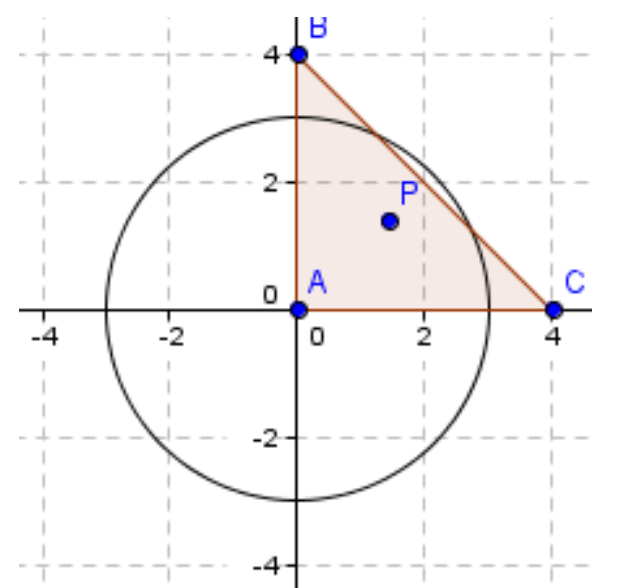

Gambar 5. Hasil Latihan bentuk Lingkaran dengan luas daerah

Pada workshop selanjutnya para peserta diharapkan akan dapat terampil dalam menuliskan rumus menggunakan aplikasi pengolah kata. Meskipun workshop yang digunakan menggunakan pengolah kata freeware namun, pada sebagian peserta meminta untuk menggunakan aplikasi pengolah kata MS. Word sehingga dalam praktik menggunakan fitur Formula. Adapun latihan dan hasilnya nampak seperti gambar berikut.
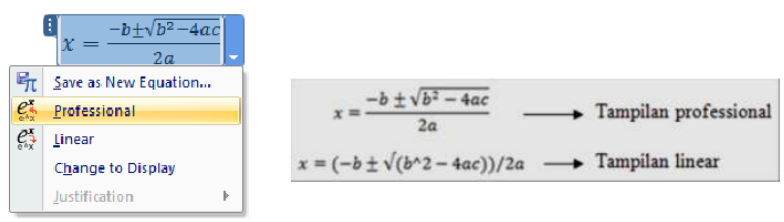

\section{Gambar 6. Latihan dan hasil fitur Formula}

Pada bagian akhir workshop, peserta diharapkan dapat membuat media pembelajaran.

Dengan mempertimbangkan hasil pengamatan terhadap kemapuan peserta, maka latihan media pembelajaran menggunakan MS Powerpoint yang menggabungkan fitur Formula dengan aplikasi Geogebra. Adapun salah satu gambar media pembelaaran peserta sebagai berikut.

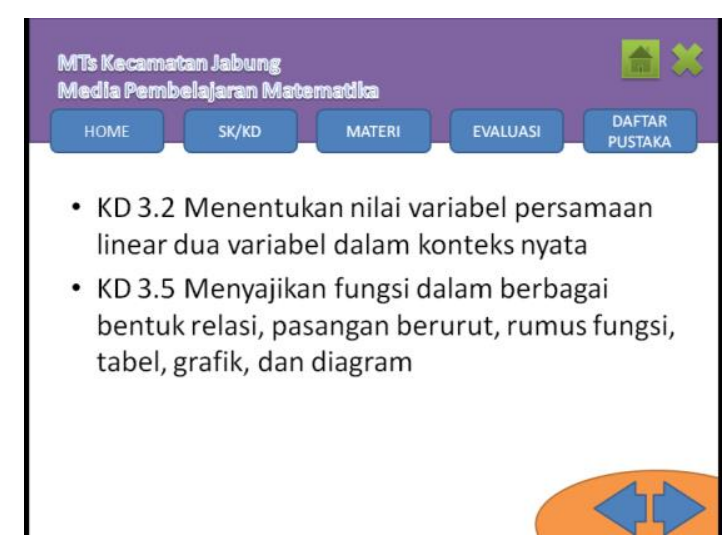

Gambar 7. Media Pembelajaran

\section{ULASAN KARYA}

Bentuk tagihan karya peserta terdapat 2 jenis, yaitu bentuk Penulisan soal serta media pembelajaran. Semua tagihan tersebut berbentuk softfile. Dengan berdasar pada hasil tagihan tersebut dapat disimpukan bahwa peserta sudah mampundalam menggunakan fitur Formula serta aplikasi Geogebra yang dipadukan dalam media pembelajaran. Kemampuan membuat media pembelajaran ini memberikan pengaruh kuta bagi peningkatan kualitas pembelajaran dalam kelas. Hal ini dibuktikan dengan respon siswa berdasarkan hasil wawancara dengan peserta. Adapun kekurangan dalam media pembelajaran ini adalah adanya kesamaan dalam media pembelajaran yang dibut, oleh karena itu dibutuhkan waktu dan semangat agar media pembelajaran yang dihasilkan akan lebih tepat sasaran sesuai kebutuhan dan keinginan peserta dan [ara siswa.

\section{DAMPAK DAN MANFAAT KEGIATAN}

Kelebihan keterampilan ini juga memiliki pengaruh terhadap guru lainnya yang masih dalam satu rayon. 
Berdasarkan hasil monitoring diketahui beberapa guru menginginkan keterampilan yang sama dan peserta memberikan panduan workshop untuk digunakan sebagai awal pengetahuan guru lain tersebut dan nantinya akan diskusi dan sharing agar dapat menguasai keterampilan-keterampilan worshop ini.

\section{KESIMPULAN}

Kegiatan PKM Guru matematika MTs Swasta kecamatan Jabung ini memiliki tingkat keberhasil tinggi. hal ini ditandai dengan pencapaian sesuai dengan permasalahan yang dimiliki oleh mitra. Pencapaian tersebut antara lain,

1. Guru sudah mendapatkan kesempatan untuk mengikuti pelatihan/workshop pemanfaatan software matematika sebagai media pembelajaran.

2. Tingginya kreatifitas guru dalam memilih model, metode atau pendekatan dalam mengajarkan konsep dasar matematika menggunakan media pembelajaran.

3. Guru atau pun sekolah telah mendapatkan informasi atau perkembangan software khususnya dalam pembelajaran matematika.

4. Tujuan sekolah/guru untuk meningkatkan kualitas sumber daya manusia sudah dilaksanakan

\section{DAFTAR PUSTAKA}

[1] K. Qamar, P. Purwanto, and M. A. Karim, "Pemanfaatan Short Message Service (SMS) dalam Remedial Teaching dengan Menggunakan Scaffolding pada Materi Peluang di SMK PGRI 3 Malang," Malang State University, 2013.

[2] K. Qamar and S. Riyadi, "Bentuk Scaffolding dalam Pembelajaran Matematika Menggunakan Aplikasi Berbasis Teks," in Prosiding SEMNASDIKMAT, 2016, vol. 1, pp. 301-305.

[3] B. Herijanto, "Pengembangan CD Interaktif Pembelajaran IPS Materi Bencana Alam," J. Educ. Soc. Stud., vol. 1, no. 1, pp. 8-12, 2012.

[4] J. I. Pendidikan, U. K. Malang, T. C. Wulandari, and U. K. Malang, "Pengembangan Modul Barisan Dan Deret," pp. 883-889.

[5] S. Riyadi, K. Qamar, and T. C. Wulandari, "Pembuatan Media Pembelajaran Berbantuan Komputer Menggunakan Aplikasi Open Source," Res. Rep., pp. 143 147, 2016.

[6] M. Hohenwarter, J. Hohenwarter, Y. Kreis, and Z. Lavicza, "Teaching and calculus with free dynamic mathematics software GeoGebra," 11th Int. Congr. Math. Educ., pp. 1-9, 2008. 